\title{
Psychosocial work environment and mental health-related long-term sickness absence among nurses
}

\author{
Corné A. M. Roelen ${ }^{1,2}$ - Marieke F. A. van Hoffen ${ }^{1,2} \cdot$ Siri Waage $^{3,4}$. \\ Wilmar B. Schaufeli ${ }^{5,6} \cdot$ Jos W. R. Twisk ${ }^{2}$ Bjørn Bjorvatn ${ }^{3,4} \cdot$ Bente E. Moen $^{7}$. \\ Ståle Pallesen ${ }^{4,8}$
}

Received: 26 April 2017 / Accepted: 2 October 2017 / Published online: 14 October 2017

(c) The Author(s) 2017. This article is an open access publication

\begin{abstract}
Purpose We investigated which job demands and job resources were predictive of mental health-related long-term sickness absence (LTSA) in nurses.

Methods The data of 2059 nurses were obtained from the Norwegian survey of Shift work, Sleep and Health. Job demands (psychological demands, role conflict, and harassment at the workplace) and job resources (social support at work, role clarity, and fair leadership) were measured at baseline and linked to mental health-related LTSA during 2-year follow-up. Cox regression models estimated hazard ratios (HR) and related 95\% confidence intervals (CI). The $c$-statistic was used to investigate the discriminative ability of the Cox regression models.
\end{abstract}

Corné A. M. Roelen

c.roelen@humancapitalcare.nl

1 HumanTotalCare, Utrecht, The Netherlands

2 Department of Epidemiology and Biostatistics, VU Medical Centre, Amsterdam, The Netherlands

3 Department of Global Public Health and Primary Care, University of Bergen, Bergen, Norway

4 Norwegian Competence Center for Sleep Disorders, Haukeland University Hospital, Bergen, Norway

5 Department of Social and Behavioural Sciences, Utrecht University, Utrecht, The Netherlands

6 Research Unit Occupational and Organizational Psychology and Professional Learning, University of Leuven, Louvain, Belgium

7 Centre for International Health, University of Bergen, Bergen, Norway

8 Department of Psychosocial Science, University of Bergen, Bergen, Norway
Results A total of 1533 (75\%) nurses were included in the analyses; 103 (7\%) of them had mental health-related LTSA during 2-year follow-up. Harassment $(\mathrm{HR}=1.07$; 95\% CI 1.01-1.17) and social support ( $\mathrm{HR}=0.92 ; 95 \%$ CI 0.87-0.98) were associated with mental health-related LTSA. However, the Cox regression model did not discriminate between nurses with and without mental health-related LTSA ( $c=0.59$; 95\% CI 0.53-0.65).

Conclusions Harassment was positively and social support at the workplace was negatively related to mental healthrelated LTSA, but both failed to discriminate between nurses with and without mental health-related LTSA during 2-year follow-up.

Keywords Absenteeism · Mental health · Nurses · Job demands-resources model $\cdot$ Psychosocial work environment $\cdot$ Sick leave

\section{Introduction}

Mental health problems are the most important contributors to illness in the workforce. In 2000, the World Health Organization estimated that $15-30 \%$ of employees will experience mental health problems during their working life (WHO 2000). Recently, the Organization for Economic Co-operation and Development (OECD) reported that 30 to $40 \%$ of all sickness absence and work disability cases within its member countries were related to mental health problems (OECD 2015). Sickness absence due to physician-diagnosed mental health symptoms (e.g. feeling anxious, nervous, stressed, depressed) or physician-diagnosed psychiatric disorders is referred to as mental health-related sickness absence. The costs of mental health-related sickness absence amount to $3-4 \%$ of the gross national product of OECD countries. This 
is partly due to the long duration of mental health-related sickness absence. A median mental health-related sickness absence duration of 3 months was reported from a Dutch occupational health service register including the sickness absence data of more than 1 million workers (Roelen et al. 2012). Nielsen et al. (2012) reported a median duration of 6 months for mental health-related sickness absence in a sample of Danish workers. Mental health-related long-term sickness absence (LTSA) disconnects employees from the workplace, which increases the risk of disability or unemployment (Henderson et al. 2011).

Work is generally beneficial for mental health (Waddell and Burton 2006). However, various physical and psychosocial aspects of work are associated with mental ill-health. Stansfeld and Candy (2006) reviewed the literature on psychosocial work environment and mental health. Most studies included in their review used the demand-control-support (DCS) model as a theoretical framework to describe the psychosocial work environment. The DCS model posits that work stress occurs in situations where psychological demands are high and job control is low. Social support received from supervisors and colleagues is assumed to buffer the effects of high psychological demands and low control (Karasek and Theorell 1990). An alternative theoretical framework that is commonly used to describe the psychosocial work environment is the effort-rewards imbalance (ERI) model. The ERI model states that the combination of putting high effort in work and receiving little rewards (e.g. salary, promotion, and esteem) increases the risk of work stress and negative health outcomes, particularly in employees who are overly committed to their work (Siegrist 1996). From their systematic review of the literature, Stansfeld and Candy (2006) concluded that high psychological demands, low decision latitude, and combinations of high efforts and low rewards were prospective risk factors for mental health problems.

The job demands-resources (JDR) model includes a wider set of work characteristics to describe the psychosocial work environment than both the DCS- and ERI models (Bakker et al. 2010). The JDR model posits that any job demand (i.e. aspect of the job that requires physical and/or psychological effort) and any job resource (i.e. aspect of the job that is functional for achieving goals and/or stimulates personal development) can affect an employee's mental health (Bakker and Demerouti 2007; Bakker et al. 2010). The impact of job demands and job resources on mental health differs across workplace settings (Schaufeli and Taris 2014). The JDR model describes a mental health impairment process, in which sustained high demands lead to work stress and burnout when employees cannot sufficiently recover from the efforts to meet high job demands. Job resources mitigate the effect of high job demands, but also drive a motivational process by facilitating the achievement of work goals and by fostering personal growth and development (Fig. 1).

\section{JDR model and mental health among nurses}

A recent study showed that employees in the healthcare sector report higher cognitive demands than employees in industry or public service (Van den Broeck et al. 2017). Besides cognitive demands, nurses experience the emotional demands of caring for patients and dealing with illness (McVicar 2003; Gelsema et al. 2006; Mealer et al. 2009; Mark and Smith 2012). Therefore, nurses may be at increased risk of mental health problems and mental healthrelated LTSA.

Using the JDR model as a theoretical framework, Hansen et al. (2009) reported that job demands in terms of workload and role conflict were associated with emotional exhaustion among Swedish nurses in acute care hospitals. In contrast, job resources (i.e. autonomy, goal clarity, work group support, supervisor support, and job challenge) were unrelated to emotional exhaustion. Jourdain and Chênevert (2010) reported that quantitative overload, role stress, work-family interference, and hostility from physicians and patients were associated with emotional exhaustion among Canadian nurses working in the public health care sector. Low psychological empowerment, poor support from supervisor and colleagues, and lack of recognition by physicians were associated with cynicism. Spence-Laschinger et al. (2012) showed that job demands (i.e. workload and bullying), but not job resources (i.e. control over work and supportive work environment), were associated with poor mental health in newly graduated Canadian nurses. Vander Elst et al. (2016) found that workload and emotional demands, but not aggression at the workplace, were positively associated with burnout among Belgian home care nurses. The job resources

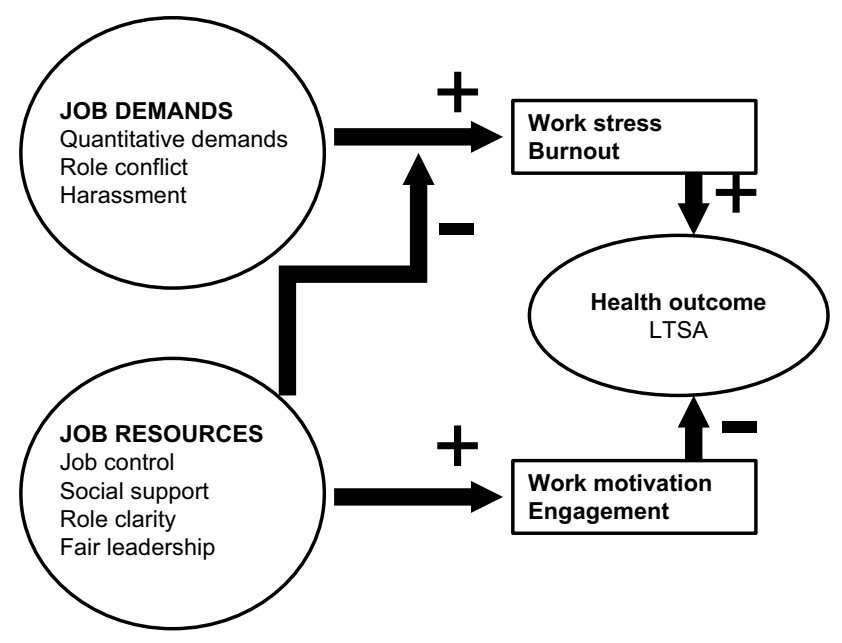

Fig. 1 The job demands-resources model 
autonomy, social support, and learning opportunities were associated with higher levels of work engagement and lower levels of burnout.

In conclusion, most studies have reported that job demands are associated with emotional exhaustion and burnout, while the effect of job resources on nurses' mental health is not yet clear. Not all nurses with mental health problems report sick. In the literature, we found no studies on the relationship of job demands and job resources with mental health-related LTSA, while sickness absence is an important issue in healthcare where nursing staff shortages are still a problem (Simoens et al. 2005; Statistics Norway 2012; Rosseter 2014). Therefore, we investigated which job demands and job resources are associated with mental health-related LTSA among nurses.

\section{Methods}

\section{Study setting and sample}

Data were retrieved from the Norwegian SUrvey of Shift work, Sleep and Health (SUSSH), which has been described previously (Reknes et al. 2014; Roelen et al. 2015). A random sample of 5400 nurses working at least $50 \%$ of a full position received a baseline survey in November 2008. For the present study, we used the data of all 2059 (38\%) nurses who completed the baseline SUSSH survey. The job demands and job resources measured by the SUSSH survey were linked to sickness absence records in 2009 and 2010 obtained from Statistics Norway. A total of 526 nurses did not give informed consent to link the survey data to their sickness absence registry data and were, therefore, excluded from the analyses. Their baseline characteristics did not differ from the 1533 nurses included in the analyses (Table 1).

\section{Job demands and resources}

The SUSSH survey measured psychological job demands, decision latitude, and social support with subscales of the Job content questionnaire (Karasek et al. 1998). Psychological demands were measured with 5 items (Crohnbach's $\alpha=0.78)$, decision latitude with 6 items $(\alpha=0.52)$, and social support at work with 6 items $(\alpha=0.82)$. Responses on all subscales were scored on a 4-point frequency scale (often-sometimes-seldom-never) and summed so that higher scores represented higher psychological demands, higher decision latitude, and higher social support at work. Based on its low Cronbach's alpha, we excluded decision latitude from the analyses.

The baseline SUSSH survey measured role clarity (3 items, $\alpha=0.77$ ), role conflict ( 3 items, $\alpha=0.73$ ), and fair leadership (3 items, $\alpha=0.73$ ) with subscales of the
General nordic questionnaire for psychological and social factors at work (Wännström et al. 2009). Responses on all subscales were scored on a 5-point frequency scale (very often-rather often-sometimes-rather seldomvery seldom) and summed so that higher scores represented higher levels of role clarity, role conflict and fair leadership.

The baseline SUSSH survey measured harassment at the workplace with the 9-item Negative Acts Questionnaire (NAQ-9, $\alpha=0.75$ ). NAQ-9 contains items on persistent criticism, gossip, offensive remarks, and threats or actual abuse by colleagues, supervisors, or patients (Einarsen et al. 2009). NAQ-9 items were scored on a 5-point frequency scale (never-now and then-monthly-weekly-daily) and a sum score was calculated if at least six NAQ-9 items had been answered, otherwise the NAQ score was set as missing; higher NAQ-9 sum scores reflected more frequent harassment.

The JDR model was used as a theoretical framework for the present study. Psychological demands, role conflict, and harassment at the workplace were considered job demands. Alternatively, social support at work, role clarity, and fair leadership were considered job resources (Fig. 1).

\section{Sickness absence}

In Norway, the first year of sickness absence is fully (i.e. $100 \%$ of the income) compensated; the employer pays the first 16 days of sickness absence and thereafter the state financially compensates sickness absence. Statistics Norway records sickness absence from the 17th sickness absence day onward, supplied with diagnostic codes of the International Classification of Primary Care (ICPC) given by the general practitioner or treating clinician. The ICPC is formally recognised by the World Health Organization (WHO) as a classification system for diseases encountered in primary care and general practice (World Organization of National Colleges, Academies and Academic Associations of General Practitioners/Family Physicians 2016). It contains categories for general and unspecified symptoms as well as disorders related to body systems, mapped in line with the International Classification of Diseases (ICD).

For this study, we obtained sickness absence data recorded by Statistics Norway in 2009 and 2010. Because Statistics Norway records sickness absence from the 17th day onward, we defined sickness absence lasting $\geq 17$ consecutive days as long-term sickness absence (LTSA). Allcause LTSA was defined as LTSA irrespective of ICPC diagnosis and mental health-related LTSA was defined as LTSA diagnosed within the ICPC category P (which corresponds to the ICD-10 chapter V of Mental and behavioural disorders). 
Table 1 Baseline characteristics of the study population $(N=2059)$

\begin{tabular}{|c|c|c|c|c|c|}
\hline & \multicolumn{2}{|c|}{ Consent $(n=1533)$} & \multicolumn{2}{|c|}{ No consent $(n=526)$} & \multirow[t]{2}{*}{ Significance level } \\
\hline & $\operatorname{Mean}\left(S D^{\mathrm{a}}\right)$ & $n(\%)$ & $\operatorname{Mean}\left(S D^{\mathrm{a}}\right)$ & $n(\%)$ & \\
\hline Age (in years) & $33.1(8.3)$ & & $33.1(7.8)$ & & $p=0.98^{\mathrm{b}}$ \\
\hline \multicolumn{6}{|l|}{ Sex } \\
\hline Women & & $1381(90)$ & & $476(90)$ & \multirow[t]{3}{*}{$p=0.73^{\mathrm{c}}$} \\
\hline Men & & $145(10)$ & & 47 (10) & \\
\hline Missing & & 7 & & 3 & \\
\hline \multicolumn{6}{|l|}{ Marital status } \\
\hline Single & & $397(26)$ & & $139(27)$ & \multirow[t]{3}{*}{$p=0.78^{c}$} \\
\hline Married/cohabiting & & $1126(74)$ & & $379(73)$ & \\
\hline Missing & & 10 & & 8 & \\
\hline \multicolumn{6}{|l|}{ Care for children at home } \\
\hline No & & $725(49)$ & & $228(49)$ & \multirow[t]{3}{*}{$p=0.06^{\mathrm{c}}$} \\
\hline Yes & & $745(51)$ & & $269(51)$ & \\
\hline Missing & & 63 & & 29 & \\
\hline \multicolumn{6}{|l|}{ Setting } \\
\hline Somatic care & & $1143(75)$ & & 409 (79) & \multirow[t]{6}{*}{$p=0.13^{\mathrm{c}}$} \\
\hline Psychiatric care & & $220(15)$ & & $61(12)$ & \\
\hline Nursing homes & & $57(4)$ & & $16(3)$ & \\
\hline Home care & & $55(4)$ & & $20(4)$ & \\
\hline Other healthcare settings & & $45(3)$ & & $15(3)$ & \\
\hline Missing & & 13 & & 5 & \\
\hline Years registered as nurse & $5.1(4.2)$ & & $5.3(4.7)$ & & $p=0.76^{\mathrm{d}}$ \\
\hline Work hours/week & $34.0(6.5)$ & & $33.6(6.7)$ & & $p=0.45^{\mathrm{d}}$ \\
\hline \multicolumn{6}{|l|}{ Psychosocial work characteristics } \\
\hline Psychological demands (5-20) & $14.3(2.7)$ & & $14.4(2.7)$ & & $p=0.29^{\mathrm{b}}$ \\
\hline Decision latitude (6-24) & $17.7(2.1)$ & & $17.6(2.1)$ & & $p=0.49^{\mathrm{b}}$ \\
\hline Social support at work (6-24) & $17.4(3.6)$ & & $17.5(3.6)$ & & $p=0.94^{\mathrm{b}}$ \\
\hline Role clarity $(1-5)$ & $4.2(0.7)$ & & $4.2(0.8)$ & & $p=0.82^{\mathrm{b}}$ \\
\hline Role conflict (1-5) & $2.7(0.8)$ & & $2.7(0.7)$ & & $p=0.91^{\mathrm{b}}$ \\
\hline Fair leadership (1-5) & $4.1(0.8)$ & & $4.1(0.8$ & & $p=0.79^{\mathrm{b}}$ \\
\hline Harassment (9-45) & $10.7(2.4)$ & & $10.6(2.4)$ & & $p=0.39^{\mathrm{b}}$ \\
\hline
\end{tabular}

The table compares the baseline characteristics of nurses who did and did not consent to linking questionnaire data to sickness absence registry data

${ }^{\text {a }}$ Standard deviation

${ }^{\mathrm{b}}$ Parametric student $t$ test

${ }^{\mathrm{c}}$ Chi-square test

${ }^{\mathrm{d}}$ Non-parametric Mann-Whitney test

\section{Data analysis}

All statistical analyses were done at the University of Bergen (Norway) in R for Windows version 3.24, using the survival package version 2.41-2 (Therneau 2017). Prospective associations were investigated by including the job demands and job resources separately as continuous independent variables in Cox regression models. Cox regression models estimate hazard ratios (HR) and related $95 \%$ confidence intervals $(\mathrm{CI})$. The $\mathrm{HR}$ can be interpreted as a relative risk on average over time; an HR $>1$ indicates an increased risk and shorter time to onset of mental health-related LTSA, whereas $\mathrm{HR}<1$ represents a reduced risk and longer time to onset of mental health-related LTSA. HRs were adjusted for the sociodemographic variables age (in years), sex (male, female), marital status (single, married/cohabiting), and care for children at home (yes, no) retrieved from the baseline SUSSH survey. Furthermore, HRs were adjusted for the work-related variables workplace setting (somatic care, psychiatric care, nursing homes, home care, and other healthcare settings), years registered as a nurse, and work hours/week addressed by the survey.

After having assessed the prospective associations with mental health-related LTSA, all job demands and 
job resources were included in a multivariable prediction model with the time to mental health-related LTSA as outcome variable. The Wald-statistic was used to assess the strength of the predictor variables: higher Wald-statistics represented stronger predictors of mental health-related LTSA. The prediction model was reduced by backward stepwise procedures using the likelihood ratio (LR) test to compare models. Akaike's Information Criterion (AIC, corresponding with $p<0.157$ ) was used as stopping rule for the backward stepwise model reduction. The concordance (c) statistic reflects the ability of the final prediction model to discriminate between nurses with and without mental health-related LTSA during 2-year follow-up (Steyerberg et al. 2010). We interpreted $c<0.60$ as failing, $0.60-0.69$ poor, $0.70-0.79$ fair, $0.80-0.89$ good, and $0.90-1.00$ as perfect discrimination.

For comparison, the same analyses were done for allcause LTSA, censoring LTSA episodes due to pregnancy, childbirth and family planning (ICPC chapter W).

\section{Results}

Data from 1533 nurses working in somatic care (75\%), psychiatric care (15\%), nursing homes (4\%), home care (4\%), and other healthcare settings (2\%) were eligible for the analyses. Their baseline characteristics are shown in Table 1.

\section{Mental health-related LTSA}

During the 2-year follow-up period, 103 (7\%) nurses had mental health-related LTSA median 305 [interquartile range (IQR) 163-401] days after baseline. Harassment was associated with a higher risk of mental health-related
LTSA, whereas the other job demands were unrelated to mental health-related LTSA (Table 2). Of the job resources, social support at work was associated with a lower risk of mental health-related LTSA.

\section{All-cause LTSA}

A total of 325 (21\%) nurses had all-cause LTSA median 294 (IQR 122-418) days after baseline. Harassment was positively associated with all-cause LTSA. The resources social support at work and fair leadership were negatively associated with all-cause LTSA. Associations between fair leadership and all-cause LTSA became non-significant after adjustment for work-related variables (Table 3).

\section{Prediction models for mental health-related and all-cause LTSA}

When all job demands and job resources were included in a multivariable prediction model, social support was the strongest predictor of both mental health-related and all-cause LTSA (Table 4). Fair leadership was the weakest predictor, but adhering to the AIC both the model predicting mental health-related LTSA (LR test $p=0.152$ ) and the model predicting all-cause LTSA (LR test $p=0.004$ ) deteriorated significantly if fair leadership was removed from the model. As a consequence, all job demands and job resources stayed in the final models. The $c$-statistics 0.59 (95\% CI $0.53-0.65)$ and 0.56 (95\% CI $0.53-0.60)$ indicated failing discrimination by the models predicting mental health-related and all-cause LTSA, respectively.

Table 2 Associations between psychosocial work characteristics and mental health-related LTSA among nurses

\begin{tabular}{lllll}
\hline & Unadjusted model & Model $1^{\mathrm{a}}$ & ${\text { Model } 2^{\mathrm{b}}}^{\text {Model3 }^{\mathrm{c}}}$ \\
\hline Job demands & & & & \\
$\quad$ Psychological demands & $1.04(0.97-1.12)$ & $1.05(0.97-1.13)$ & $1.02(0.93-1.12)$ & $1.03(0.93-1.14)$ \\
Role conflict & $1.17(0.92-1.50)$ & $1.24(0.95-1.62)$ & $1.12(0.71-1.46)$ & $1.25(0.72-1.52)$ \\
$\quad$ Harassment & $1.06(1.00-1.14)^{*}$ & $1.08(1.01-1.16)^{*}$ & $1.02(0.93-1.12)$ & $1.06(1.01-1.19)^{*}$ \\
Job resources & & & & \\
$\quad$ Social support at work & $0.92(0.88-0.97)^{* *}$ & $0.92(0.87-0.97)^{* *}$ & $0.93(0.87-0.97)^{* *}$ & $0.93(0.86-0.98)^{* *}$ \\
Role clarity & $0.80(0.61-1.05)$ & $0.80(0.60-1.06)$ & $0.92(0.66-1.21)$ & $0.82(0.65-1.11)$ \\
Fair leadership & $0.84(0.66-1.07)$ & $0.89(0.69-1.15)$ & $0.87(0.70-1.23)$ & $0.90(0.64-1.28)$ \\
\hline
\end{tabular}

The table shows hazard ratios and related $95 \%$ confidence intervals; HR $>1$ indicates a shorter and $\mathrm{HR}<1$ a longer time to onset of mental health-related LTSA

* Significant at $5 \%$ and ** significant at $1 \%$ level

${ }^{a}$ Model 1 adjusted for sociodemographic variables: age, sex, marital status, and care for children at home

${ }^{\mathrm{b}}$ Model 2 adjusted for work-related variables: workplace setting, years registered as nurse, and work hours/week

${ }^{\mathrm{c}}$ Model 3 fully adjusted for sociodemographic and work-related variables 
Table 3 Associations between psychosocial work characteristics and all-cause LTSA among nurses

\begin{tabular}{lllll}
\hline & Unadjusted model & Model 1 & Model $^{\mathrm{b}}$ & Model $^{\mathrm{c}}$ \\
\hline Job demands & & & & \\
$\quad \begin{array}{l}\text { Psychological demands } \\
\text { Role conflict }\end{array}$ & $1.04(0.99-1.08)$ & $1.04(0.99-1.09)$ & $1.02(0.97-1.07)$ & $1.02(0.96-1.07)$ \\
Harassment & $1.00(0.85-1.17)$ & $1.04(0.88-1.22)$ & $1.03(0.89-1.21)$ & $1.07(0.91-1.29)$ \\
Job resources & $1.06(1.01-1.10)^{*}$ & $1.06(1.01-1.11)^{*}$ & $1.05(1.01-1.10)^{*}$ & $1.06(1.02-1.11)^{*}$ \\
$\quad$ Social support at work & $0.96(0.92-0.99)^{*}$ & $0.96(0.92-0.99)^{*}$ & $0.97(0.93-1.00)^{*}$ & $0.95(0.91-0.99)^{* *}$ \\
Role clarity & $0.96(0.81-1.15)$ & $0.95(0.80-1.14)$ & $0.99(0.83-1.20)$ & $0.99(0.82-1.20)$ \\
Fair leadership & $0.83(0.71-0.96)^{*}$ & $0.84(0.72-0.98)^{*}$ & $0.87(0.75-1.02)$ & $0.90(0.75-1.07)$ \\
\hline
\end{tabular}

The table shows hazard ratios and related 95\% confidence intervals; HR $>1$ indicates a shorter and $\mathrm{HR}<1$ a longer time to onset of mental health-related LTSA;

* Significant at $5 \%$ and $* *$ significant at $1 \%$ level

${ }^{a}$ Model 1 adjusted for sociodemographic variables: age, sex, marital status, and care for children at home

${ }^{\mathrm{b}}$ Model 2 adjusted for work-related variables: workplace setting, years registered as nurse, and work hours/ week

${ }^{c}$ Model 3 fully adjusted for sociodemographic and work-related variables
Table 4 Multivariable prediction model including all job demands and job resources

\begin{tabular}{llllll}
\hline & \multicolumn{2}{l}{$\begin{array}{l}\text { Mental health-related } \\
\text { LTSA }\end{array}$} & & \multicolumn{2}{l}{ All-cause LTSA } \\
\cline { 2 - 3 } \cline { 5 - 6 } \cline { 5 - 6 } & $B(\mathrm{SE})$ & Wald & & $B(\mathrm{SE})$ & Wald \\
\hline $\begin{array}{l}\text { Psychological } \\
\quad \text { demands }\end{array}$ & $0.012(0.046)$ & 0.074 & & $0.021(0.028)$ & 0.571 \\
$\begin{array}{l}\text { Role conflict } \\
\text { Harassment }\end{array}$ & $0.009(0.174)$ & 0.003 & & $0.010(0.019)$ & 0.272 \\
$\begin{array}{l}\text { Social support at } \\
\quad \text { work }\end{array}$ & $-0.017(0.014)$ & 1.474 & & $0.197(0.085)$ & 5.380 \\
$\quad \begin{array}{l}\text { Role clarity } \\
\text { Fair leadership }\end{array}$ & $-0.07(0.037)$ & 4.312 & & $-0.227(0.092$ & 6.138 \\
\hline
\end{tabular}

The table shows Cox regression coefficients $(B)$, related standard errors (SE), and the Wald-statistic (higher Wald-statistics reflect stronger predictors of (mental health-related) long-term sickness absence (LTSA)

\section{Discussion}

The present study showed that harassment at the workplace was associated with an increased risk of mental health-related LTSA among nurses. Social support at work was associated with a reduced risk of mental healthrelated LTSA. However, a prediction model including harassment and social support failed to discriminate between nurses with and without mental health-related LTSA during 2-year follow-up.

\section{Job demands, job resources and mental health-related LTSA}

We found that harassment at the workplace was an important risk factor for mental health-related LTSA among nurses. A recent review of the literature showed that one-third of the nurses worldwide are exposed to physical violence, and two-thirds are exposed to non-physical violence (Spector et al. 2014). Harassment and other negative acts at the workplace have been associated with poor health outcomes among nurses (Vessey et al. 2010; Li and Zhang, 2010; Allen et al. 2015). Previously, Reknes et al. (2014) found reciprocal relationships between bullying and mental health. The authors showed that bullying behaviours at baseline predicted increased symptoms of anxiety and fatigue 1 year later. Conversely, symptoms of anxiety, depression and fatigue at baseline predicted increased exposure to bullying 1 year later. Our present study adds that harassment at the workplace increases the risk of future mental health-related LTSA in nurses.

The literature on associations of job demands and job resources with mental health-related LTSA is scarce. In a cross-sectional study of a sample of Swedish council employees, psychological demands and role conflict were positively correlated, whereas role clarity, support from the supervisor and co-workers, and fair leadership were negatively correlated with mental health-related LTSA (Wännström et al. 2009). In the present prospective study, we found that social support was negatively associated with mental health-related LTSA among nurses. Fair leadership was associated with all-cause, but not mental health-related LTSA. We failed to find significant associations of psychological demands and role conflict with (mental healthrelated) LTSA among nurses. These different findings may 
be due to differences in study population and design. Crosssectional correlations between self-reported psychosocial work characteristics and mental health-related LTSA may have been inflated if subjects with poor mental health perceive work characteristics more negatively than healthy subjects (De Lange et al. 2004).

An alternative explanation for the different findings might be diagnostic misclassification. For example, if nurses with mild mental disorders present with non-specific symptoms such as tiredness and listlessness, they were classified within the ICPC category A of general and unspecified symptoms. In the same vein, nurses presenting with headache, muscle pain, or other psychosomatic symptoms may have been misclassified within the ICPC N (neurological), L (musculoskeletal), or other somatic categories, respectively. For this reason and to compare our present results with those of previous studies, we investigated associations between psychosocial working conditions and all-cause LTSA.

\section{Job demands, job resources and all-cause LTSA}

Some studies have used the JDR model as a theoretical framework to investigate the effect of job demands and job resources on LTSA irrespective of diagnosis (Bakker et al. 2003a, b; Schaufeli et al. 2009). However, few studies were conducted in the healthcare sector. Clausen et al. (2012) reported that emotional, but not cognitive demands were associated with an increased risk of LTSA in Danish eldercare workers. This corroborates our finding that psychological demands were not associated with LTSA. Unfortunately, the SUSSH survey did not measure emotional demands. In contrast to our findings, Clausen et al. (2012) found that role conflict was positively associated with LTSA in Danish eldercare workers. Possibly, role conflicts were more of a problem in the Danish eldercare workers, given the fact that the levels of role conflict measured by Clausen and colleagues were twice the levels measured in the present study. Our finding that fair leadership and social support at work were associated with a reduced risk of all-cause LTSA was in agreement with the results of Clausen et al. (2012), who showed that the quality of leadership and a good team climate were associated with a reduced risk of LTSA among Danish eldercare workers.

In a later study, Clausen et al. (2014) reported that high job demands (workplace and psychological demands) and low job resources (influence at work and quality of leadership) were associated with a higher LTSA risk among 39,408 Danish workers employed in various occupations. These findings not only differ from our present results, but also from Clausen's previous findings in the healthcare sector (Clausen et al. 2012), indicating that the associations of job demands and job resources with LTSA vary across working populations and workplace settings (Schaufeli and Taris 2014).

\section{Strengths and limitations}

The prospective design and the use of recorded sickness absence data were significant assets of the present study. Still, there are some methodological limitations that should be mentioned. First, the baseline SUSSH response rate was $38 \%$, which could have introduced selection bias at the start of SUSSH. It has been reported that healthy subjects are more inclined to participate in health surveys than subjects with health problems (Etter and Perneger 1997). Such healthy-volunteer bias may have led to an underestimation of associations between psychosocial work characteristics and (mental health-related) LTSA.

Furthermore, nurses with stress-related disorders who presented with non-specific symptoms (e.g. tiredness and listlessness) or somatic symptoms (e.g. headache, muscle pain) may have been classified in ICPC categories other than the P-category and were, therefore, not regarded as having mental health-related LTSA. Consequently, the present results might particularly apply to nurses with specific mental disorders, such as depressive and anxiety disorders rather than non-specific stress-related disorders. In that regard, it is interesting to note that systematic reviews of the literature have provided evidence for an association between low social support at work and depression (Bonde 2007; Netterstrom et al. 2008).

\section{Practical implications and directions for further research}

The current findings are important for nurse managers, as the results show that nurse managers can play a prominent role in reducing LTSA, for example by encouraging social support and creating a good social climate in nursing teams. We measured fair leadership by asking nurses if their managers treated them fairly and distributed work equally and impartially across the team. Thus, nurse managers could reduce LTSA by fairly treating their personnel and fairly distributing work over their nursing teams. In a systematic review of the literature, Cummings et al. (2010) found evidence for better health outcomes in nurses of teams led by supportive managers as compared to task-oriented or laissezfaire managers. Schreuder et al. (2011) showed that teams led by relationship-oriented nurse managers had fewer sickness absence days than teams lead by task-oriented nurse managers.

The relationship between job demands, job resources, and (mental health-related) LTSA differs across working populations and workplace settings. The nurses included in SUSSH came from various workplace settings from all over Norway. 
We presume that harassment and social support at the workplace are general risk factors of mental health-related LTSA among nurses. However, we could not rule out that other psychosocial work characteristics play an important role at the organizational level. For example, psychological demands may be a risk factor in wards where workload and time pressure are high. Hence, nurse managers should consider measuring job demands and job resources in their ward to find grounds for managing mental health-related LTSA.

Although associated with future mental health-related LTSA, harassment and social support at the workplace failed to discriminate between nurses with and without mental health-related LTSA during the 2-year follow-up period. Probably, the discriminative ability of job demands and resources is limited because psychosocial work characteristics vary across workplace settings. Furthermore, there are indications that the associations between job demands, job resources, and LTSA are moderated by other factors, such as work-home interference (Van der Heijden et al. 2008) and work engagement (García-Sierra et al. 2016). Future studies could investigate if these moderating factors add to the discrimination between nurses with and without mental health-related LTSA. Besides measuring the experienced levels of job demands and job resources, it would be interesting to investigate how workers value job demands and job resources (Abma et al. 2016). Demands and resources valued important for a given workplace setting may better discriminate between workers with and without LTSA than job demands and job resources which are not valued important.

\section{Conclusions}

Harassment at the workplace was associated with an increased risk of mental health-related LTSA and social support at the workplace was associated with a reduced risk of mental health-related LTSA. However, job demands and job resources failed to identify nurses at increased risk of mental health-related LTSA.

\section{Compliance with ethical standards}

Funding The longitudinal Survey of Shift work, Sleep and Health (SUSSH) was funded by the Health Authorities Western Norway Helse Vest, Nordforsk Nordic Program on Health and Welfare, and the Norwegian Nurses Organization. The present study used SUSSH data for secondary analyses, but was not funded.

Conflict of interest The authors declare that they have no conflict of interest.

Ethical approval The Survey of Shift work, Sleep, and Health (SUSSH) was conducted in accordance with the ethical standards of the Regional Committee for Medical Research Ethics West-Norway (REK-WEST 088.08) and with the 1964 Helsinki declaration and its later amendments or comparable ethical standards. The Norwegian Data Inspectorate gave formal consent for the use of SUSSH data for the present study.

Open Access This article is distributed under the terms of the Creative Commons Attribution 4.0 International License (http://creativecommons.org/licenses/by/4.0/), which permits unrestricted use, distribution, and reproduction in any medium, provided you give appropriate credit to the original author(s) and the source, provide a link to the Creative Commons license, and indicate if changes were made.

\section{References}

Abma FI, Brouwer S, de Vries HJ, Arends I, Robroek SJW, Cuijpers MPJ, van der Wilt JG, Bültmann U, van der Klink JJL (2016) The capability set for work: development and validation of a new questionnaire. Scand J Work Environ Health 42:34-42

Allen BC, Holland P, Reynolds R (2015) The effect of bullying on burnout in nurses: the moderating role of psychological detachment. J Adv Nurs 71:381-390

Bakker AB, Demerouti E (2007) The job demands-resources model: state of the art. J Manag Psychol 22:309-328

Bakker AB, Demerouti E, de Boer E, Schaufeli WB (2003a) Job demands and job resources as predictors of absence duration and frequency. J Vocat Behav 63:341-356

Bakker AB, Demerouti E, Schaufeli WB (2003b) A multi-group analysis of the job demands-resources model. Eur J Work Organ Psychol 12:393-417

Bakker A, van Veldhoven MJPM, Xanthopoulou D (2010) Beyond the demand-control model: thriving on high job demands and resources. J Person Psychol 9:3-16

Bonde JPE (2007) Psychosocial factors at work and risk of depression: a systematic review of the epidemiological evidence. Occup Environ Med 65:438-445

Clausen T, Nielsen K, Carneiro IG, Borg V (2012) Job demands, job resources and long-term sickness absence in Danish eldercare services: a prospective analysis of register-based outcomes. J Adv Nurs 68:127-136

Clausen T, Burr H, Borg V (2014) Do psychosocial job demands and job resources predict long-term sickness absence? An analysis of register-based outcomes using pooled data on 39,408 individuals in four occupational groups. Int Arch Occup Environ Health 87:909-917

Cummings G, MacGregor T, Davey M, Lee H, Wong C, Lo E, Stafford E (2010) Leadership styles and outcome patterns for the nursing workforce and work environment: a systematic review. Int J Nurs Stud 47:363-385

De Lange AH, Taris TW, Kompier MAJ, Houtman ILD, Bongers PM (2004) The relationships between work characteristics and mental health: examining normal, reversed, and reciprocal relationships in a 4-wave study. Work Stress 18:149-166

Einarsen S, Hoel H, Notelaers G (2009) Measuring exposure to bullying and harassment at work: validity, factor structure and psychometric properties of the negative acts questionnaire-revised. Work Stress 23:24-44

Etter JF, Perneger TV (1997) Analysis of non-response bias in a mailed health survey. J Clin Epidemiol 50:1123-1128

García-Sierra R, Fernández-Castro J, Martínez-Zaragoza F (2016) Relationship between job demand and burnout in nurses: does it depend on work engagement? J Nurs Manag 24:780-788 
Gelsema T, van der Doef M, Maes S, Janssen M, Akerboom S, Verhoeven C (2006) A longitudinal study of job stress in the nursing profession: causes and consequences. J Nurs Manag 14:289-299

Hansen N, Sverke M, Näswall K (2009) Predicting nurse burnout from demands and resources in three acute care hospitals under different forms of ownership: a cross-sectional questionnaire survey. Int J Nurs Stud 46:95-107

Henderson M, Harvey SB, Øverland S, Mykletun A, Hotopf M (2011) Work and common psychiatric disorders. J R Soc Med 104:198-207

Jourdain G, Chênevert D (2010) Job demands-resources, burnout and intention to leave the nursing profession: a questionnaire survey. Int J Nurs Stud 47:709-722

Karasek R, Theorell T (1990) Healthy work: stress, productivity, and the reconstruction of working life. Basic Books, New York

Karasek R, Brisson C, Kawakami N, Houtman I, Bongers P, Amick B (1998) The job content questionnaire (JQC): an instrument for internationally comparative assessments of psychosocial job characteristics. J Occp Health Psychol 3:322-355

Li Y-X, Zhang L (2010) Relationship of workplace bullying with job burnout, job satisfaction and health in nurses. Chin Ment Health J 24:632

Mark G, Smith AP (2012) Occupational stress, job characteristics, coping, and the mental health of nurses. Br J Health Psychol 17:505-521

McVicar A (2003) Workplace stress in nursing: a literature review. J Adv Nurs 44:633-642

Mealer L, Burnham E, Goode C, Rothbaum B, Moss M (2009) The prevalence and impact of post-traumatic stress disorder and burnout in nurses. Depress Anxiety 26:1118-1126

Netterstrom B, Conrad N, Bech P, Fink P, Olson O, Rugulies R, Stansfeld S (2008) The relation between work-related psychosocial factors and the development of depression. Epidemiol Rev 30:118-132

Nielsen MB, Bültmann U, Madsen IE, Martin M, Christensen U, Diderichsen F, Rugulies R (2012) Health, work, and personalrelated predictors of time to return to work among employees with mental health problems. Disabil Rehabil 34:1311-1316

OECD (2015) Fit mind, fit job. From evidence to practice in mental health and work. OECD, Paris

Reknes I, Pallesen S, Magerøy N, Moen BE, Bjorvatn B, Einarsen S (2014) Exposure to bullying behaviors as a predictor of mental health problems among Norwegian nurses: results from the prospective SUSSH-survey. Int J Nurs Stud 51:479-487

Roelen CA, Norder G, Koopmans PC, van Rhenen W, van der Klink JJ, Bültmann U (2012) Employees sick-listed with mental disorders: who returns to work and when? J Occup Rehabil 22:409-417

Roelen CA, Heymans MW, Twisk JW, van Rhenen W, Pallesen S, Bjorvatn B, Moen BE, Magerøy N (2015) Updating and prospective validation of a prognostic model for high sickness absence. Int Arch Occup Environ Health 88:113-122

Rosseter RJ (2014) Nursing shortage fact sheet. http://www.aacn.nche. edu/media-relations/fact-sheets/nursing-shortage. Accessed 09 July 2017

Schaufeli WB, Taris TW (2014) A critical review of the Job demandsresources model: implications for improving work and health. In: Bauer G, Hämmig O (eds) Bridging occupational, organizational and public health: a transdisciplinary approach. Springer, Dordrecht, pp 43-68
Schaufeli WB, Bakker AB, van Rhenen W (2009) How changes in job demands and resources predict burnout, work engagement, and sickness absenteeism. J Organ Behav 30:893-917

Schreuder JA, Roelen CA, van Zweeden N, Jongsma D, van der Klink JJ, Groothoff JW (2011) Leadership styles of nurse managers and registered sickness absence among their nursing staff. Health Care Manag Rev 36:58-66

Siegrist J (1996) Adverse health effects of high-effort/low-reward conditions. J Occup Health Psychol 1:27-41

Simoens S, Villeneuve M, Hurst J (2005) Tackling nurse shortages in OECD countries. OECD health working papers no 19. OECD, Paris

Spector PE, Zhou ZE, Che XX (2014) Nurse exposure to physical and nonphysical violence, bullying, and sexual harassment: a quantitative review. Int J Nurs Stud 51:72-84

Spence-Laschinger HK, Grau AL, Finegan J, Wilk P (2012) Predictors of new graduate nurses' workplace well-being: testing of the job demands-resources model. Health Care Manag Rev 37:175-186

Stansfeld S, Candy B (2006) Psychosocial work environment and mental health - a meta-analytic review. Scand J Work Environ Health 32:443-462

Statistics Norway (2012) https://www.ssb.no/forskning/mikrookonomi/ arbeidsmarked/betydelig-underdekning-av-helsepersonell-i-2035 [Norwegian]. Accessed 09 July 2017

Steyerberg EW, Vickers AJ, Cook NR, Gerds T, Gonen M, Obuchowski N, Pencina MJ, Kattan MW (2010) Assessing the performance of prediction models: a framework for some traditional and novel measures. Epidemiology 21:128-138

Therneau TM (2017) Survival analysis. https://cran.r-project.org/web/ packages/survival/survival.pdf. Accessed 09 July 2017

Van den Broeck A, vander Elst T, Baillien E, Sercu M, Schouteden M, de Witte H, Godderis L (2017) Job demands, job resources, burnout, work engagement, and their relationships: an analysis across sectors. J Occup Environ Med 59:369-476

Van der Heijden BI, Demerouti E, Bakker AB, the NEXT study group coordinated by Hasselhorn H-M (2008) Work-home interference among nurses: reciprocal relationships with job demands and health. J Adv Nurs 62:572-584

Vander Elst T, Cavents C, Daneels K, Johannik K, Bailien E, van den Broeck A, Godderis L (2016) Job demands-resources predicting burnout and work engagement among Belgian home health care nurses: a cross-sectional study. Nurs Outlook 64:542-556

Vessey JA, Demarco R, DiFazio R (2010) Bullying, harassment, and horizontal violence in the nursing workforce: the state of the science. Ann Rev Nurs Res 28:133-157

Waddell G, Burton A (2006) Is work good for your health and wellbeing?. The Stationery Office, London

Wännström I, Peterson U, Åsberg M, Nygren Å, Gustavsson JP (2009) Psychometric properties of scales in the general nordic questionnaire for psychological and social factors at work (QPSnordic): confirmatory factor analysis and prediction of certified long-term sickness absence. Scand J Psychol 50:231-244

WHO (2000) Mental health and work: impact, issues, and good practices. WHO Publications, Geneva

World Organization of National Colleges, Academies and Academic Associations of General Practitioners/Family Physicians (2016) http://www.kith.no/upload/2705/ICPC-2-English.pdf. Accessed 09 July 2017 